\title{
Currículo e diversidade: os desafios da inclusão escolar de alunos com deficiência intelectual
}

\author{
Érika Soares de Oliveira \\ Secretaria Municipal de Educação de Natal \\ Lúcia de Araújo Ramos Martins \\ Universidade Federal do Rio Grande do Norte
}

\section{Resumo}

Este trabalho registra aspectos de uma pesquisa que objetivou analisar o currículo de uma escola municipal, situada na cidade de Natal/RN, com vistas à inclusão de alunos com deficiência intelectual. Com base num estudo de caso, apresentamos algumas reflexões acerca das concepções de currículo escolar, sob a ótica da inclusão escolar. Assim, destacamos a compreensão das professoras, coordenadoras e gestora sobre a inserção dessa temática no projeto político-pedagógico, a concepção de currículo, bem como as diretrizes curriculares expressas no projeto político pedagógico. Constatamos que as diretrizes curriculares expressam uma visão ampla de currículo e são desconhecidas pelos profissionais da instituição de ensino.

Palavras-chave: Currículo. Inclusão escolar. Deficiência intelectual. 


\section{Curriculum and diversity: the challenges of the inclusion of school students with intellectual disabilities}

This paper reports aspects of a study aimed at analyzing the curriculum of a public school, under the administration of the municipality, in the city of Natal/RN, with the purpose of verifying if the curriculum has aspects of inclusion for students with intellectual disabilities. Based on a case study, we present some reflections on the conceptions of the curriculum, from the perspective of school inclusion. For this end, we emphasize the understanding of teachers, coordinators and the principal about the insertion of this theme in the pedagogicalpolicy project and the conception of the curriculum, as well as the curriculum guidelines, as expressed in the pedagogical-policy project. We found that the official curriculum guidelines express a broad vision of the curriculum, but are unknown to the professionals of the educational institution.

Keywords: Curriculum. School inclusion. Intellectual disabilities.

\section{Currículo y diversidad: los desafíos de la inclusión escolar de los alumnos con discapacidad intelectual}

Este trabajo reporta a los aspectos de un estudio que tuvo como objetivo analizar el plan de estudios de una escuela municipal, ubicada en Natal/RN, con miras a la inclusión de alumnos con discapacidad intelectual. Basado en un estudio de caso, se presentan algunas reflexiones sobre las concepciones del plan de estudios desde la perspectiva de la inclusión escolar. Por lo tanto, hacemos destaque en la comprensión de los profesores, coordinadores y administradores, en la inclusión de esta cuestión en el proyecto político-pedagógico, el diseño del plan de estudios y lineamientos curriculares expresados en el proyecto político pedagógico. Tomamos nota de que los lineamientos curriculares expresan una visión amplia del currículo y son ignorados por la institución de educación profesional.

Palabras clave: Currículo. Inclusión en la escuela. Discapacidad intelectual. 


\section{Introdução}

Um dos desafios da educação contemporânea é assegurar a todas as pessoas, inclusive àquelas que apresentam algum tipo de deficiência, a permanência e a aprendizagem, com qualidade, na escola regular. Isso evidencia o reconhecimento de que não basta apenas matricular aqueles que a procuram, mas é preciso atendê-los dentro de uma pedagogia centrada no aluno, que respeite o seu ritmo de aprendizagem e atue com o objetivo de the proporcionar uma formação cidadã.

A partir dessa concepção, destacamos os princípios orientadores de um sistema educacional que se proponha, efetivamente, a inclusão escolar dos alunos, a partir do reconhecimento e da resposta

[...] às diversas dificuldades de seus alunos, acomodando os diferentes estilos e ritmos de aprendizagem e assegurando uma educação de qualidade para todos mediante currículos apropriados, modificações organizacionais, estratégias de ensino, recursos e parcerias com suas comunidades. A inclusão, na perspectiva de um ensino de qualidade para todos, exige da escola brasileira novos posicionamentos que implicam num esforço de atualização e reestruturação das condições atuais, para que o ensino se modernize e para que os professores se aperfeiçoem, adequando as ações pedagógicas à diversidade dos aprendizes. (Schneider, 2004, p.1)

Nessa perspectiva, a diferença é vista como algo inerente à condição humana e à relação entre todas as pessoas. Ao mesmo tempo em que há o reconhecimento de que existem características comuns a todos, também há o reconhecimento de que cada ser humano é único e apresenta características e necessidades específicas. Os alunos e alunas, de uma maneira geral, têm diferentes estilos, ritmos, talentos e preferências de aprendizagem. A escola inclusiva surge, exatamente, para fazer esse reconhecimento, discutindo as diferenças, respondendo à heterogeneidade, valorizando a diversidade e incentivando a autonomia.

Construir uma escola inclusiva, de qualidade social, que atenda aos interesses e às necessidades da comunidade escolar, requer diversas mudanças, a começar pela reflexão sobre o direito à educação e sobre a percepção existente em relação à inclusão escolar de pessoas que apresentam deficiência. Tal reflexão deve contribuir para a construção de elementos que favoreçam um trabalho pedagógico capaz de contemplar as especificidades desse alunado.

Incluir exige uma ação conjunta dos envolvidos no processo educacional, novos posicionamentos, reflexões efetivas sobre a prática educativa, a fim de promover a aprendizagem de todos os alunos. Trata-se de reconhecer que as dificuldades que os alunos apresentam não são apenas deles, visto que resultam, em grande parte, do 
modo como a educação é concebida e colocada em prática. A partir do momento em que a escola compreende e implementa, na construção do seu currículo, princípios que subsidiem uma prática pedagógica favorecedora da aprendizagem de todos, consequentemente busca estratégias e alternativas capazes de tornar possível uma formação de acordo com o ritmo de cada um.

Tratam-se, portanto, de princípios voltados para a discussão, respeito e valorização das diferenças individuais, logo, para a compreensão de que todas as pessoas são capazes de aprender, dentro das suas possibilidades. Por isso, requer-se um currículo aberto, preocupado com a seleção e organização dos conteúdos pautadas nas necessidades dos alunos, flexível na definição dos objetivos, com a diversificação dos procedimentos adotados, bem como com o planejamento das atividades de ensino-aprendizagem com base no nível de aprendizagem dos alunos.

Assim, um currículo pautado nesses princípios significa “[...] um currículo comum a todos os alunos que garanta um ensino com níveis diversificados e dê aos alunos de todos os níveis oportunidade de se envolverem de forma positiva nas actividades da classe" (Porter, 1997, p. 44).

Nesse sentido, entendemos que o currículo construído e implementado com base nas diferenças apresentadas pelos alunos caracteriza-se como um elemento determinante no processo de ensino-aprendizagem, visto que prevê orientações capazes de favorecer a participação efetiva de todos. Isso porque o que os alunos com deficiência requerem “[...] não é algo radicalmente diferente de outras crianças, mas o que todas as crianças necessitam: um melhor e mais vigoroso currículo, desenvolvido por intermédio de uma pedagogia mais variada e ilustrada" (Hart apud Torres Gonzàlez, 2002, p. 117).

Frente a esse contexto, no decorrer desse trabalho buscamos apresentar algumas reflexões acerca das concepções que permeiam o currículo escolar, sob a ótica da inclusão educacional de pessoas com deficiência intelectual. Com isso, destacamos a compreensão das professoras, coordenadoras e gestora de uma instituição escolar, no que se refere à inserção dessa temática no Projeto Político Pedagógico (PPP); e a concepção de currículo e o conhecimento das diretrizes curriculares expressas no PPP.

\section{A pesquisa}

O estudo empreendido visou analisar o currículo de uma escola municipal da cidade de Natal - RN, com vistas ao atendimento educacional inclusivo de alunos com deficiência intelectual. De maneira específica, objetivou verificar como é operacionalizado o currículo na prática pedagógica da sala de aula. 
A escola que foi campo de nossa pesquisa recebe crianças da Educação Infantil e do $2^{\circ}$ ao $5^{\circ}$ ano do Ensino Fundamental. Atendeu, em 2008' , a quatrocentos e dezoito alunos, sendo que, destes, quatro apresentam algum tipo de deficiência; dentre eles, três apresentavam deficiência intelectual (sendo um com síndrome de Down, e os outros dois cuja etiologia da deficiência apresentada ainda não havia sido detalhada), e um que apresentava deficiência auditiva.

\section{Aspectos metodológicos}

Para realização deste trabalho utilizamos uma abordagem de cunho qualitativo, que, conforme explicita Goldenberg (2003, p. 14), caracteriza-se pelo fato do pesquisador estar centrado no "[...] aprofundamento da compreensão de um grupo social, de uma organização [...]", possibilitando a investigação do aspecto estudado na sua complexidade, dentro de um contexto natural. Optamos pelo estudo de caso, que, conforme detalha Gil (1999, p. 78), pode ser caracterizado como "[...] um estudo profundo e exaustivo de um ou de poucos objetos, de maneira a permitir conhecimento amplo e detalhado do mesmo". Nessa perspectiva, abrange uma temática atual, dentro de seu contexto real, principalmente quando não há clareza entre o tema a ser investigado e o contexto.

Para fins desse trabalho, centramo-nos na análise do currículo situado no Projeto Político Pedagógico (PPP) da escola, a fim de conhecermos as diretrizes que orientam o desenvolvimento da ação pedagógica dos docentes diante da inclusão de alunos com deficiência intelectual, bem como na busca pela apreensão de significados na fala dos sujeitos investigados, relacionada ao contexto em que estão inseridos e baseada na concepção teórica do pesquisador, favorecendo um olhar pautado na qualidade (Fernandes apud Alves; Silva, 1992).

\section{O currículo: uma análise das concepções}

O currículo é um caminho, não é um lugar. É construído no caminho, com base numa história que precisa ser contada. Assim, toda proposta contém uma aposta, evidenciando as crenças que a escola tem nas possibilidades dos alunos, apostando nas suas potencialidades e em seu avanço educacional. Toda proposta é situada, reflete o lugar de onde se fala e os valores que a constituem, bem como as dificuldades que enfrenta,

1. Período em que desenvolvemos o Estudo de Caso na escola. 
os problemas que precisam ser superados e a direção que a orienta. Essa visão é a expressão de um desejo que aponta um caminho a construir (Kramer, 2006).

A partir da análise do Projeto Político Pedagógico da escola campo de pesquisa, pudemos constatar a existência de diretrizes curriculares, definindo o currículo como elemento que engloba todas as atividades propostas pela escola. Nesse sentido, propunha a diversificação e flexibilidade, no intuito de motivar o aluno e atender ao seu nível de aprendizagem.

Nesse contexto, expressava cuidado ao selecionar os conteúdos programáticos numa sequência lógica e com significância, no intuito de permitir a formação de cidadãos conscientes, críticos e capazes de contribuir com a transformação da sociedade. Ressaltava, ainda, que essa formação devia estar em consonância com os Parâmetros Curriculares Nacionais (Projeto Político Pedagógico, 2005).

Diante dos aspectos contemplados no PPP, para compreendermos a linha teórica que envolvia o currículo vigente e orientava a prática pedagógica da escola, abordamos a concepção das várias profissionais pesquisadas (gestora, coordenadoras e professoras), que representam alguns segmentos escolares a abordarem o currículo.

Pudemos verificar, através das falas dos sujeitos, a polissemia do termo currículo sendo evidenciada em várias compreensões, bem como a influência de várias linhas teóricas, uma vez que elas o percebiam como:

Toda a proposta que a gente pode ter em relação aos conteúdos, disciplinas, à necessidade do aluno e que deve estar de acordo com a realidade da clientela (Gestora Gelsa). [...] são as diretrizes do processo de ensino-aprendizagem da escola, as especificações concernentes a cada etapa de aprendizagem [...] (Coordenadora Suzana).

Currículo, pra mim, nunca ficou muito claro, assim, mas, pelo menos quando a gente fez o da outra escola, a gente pensou em elaborar, em montar a questão dos conteúdos programáticos de uma série, de uma disciplina pra outra, e as ações, as atividades, a metodologia, tudo entra (Coordenadora Tércia).

0 currículo são as disciplinas trabalhadas (Profa Deise).

0 currículo deve contemplar o que a escola entende, não só a questão dos conteúdos, mas as habilidades. Tudo o que a escola entende que é importante pra aquele aluno ser trabalhado, deve estar contemplado no currículo (Profa Valquíria).

As referências feitas pelos sujeitos pesquisados ao termo currículo refletem a complexidade dos significados que lhe são atribuídos. Com isso constatamos, tanto na fala da gestora como na das coordenadoras e da professora Valquíria², uma compreensão ampla do que propõe o currículo, constituindo-se como orientador da prática educativa,

2. Todos os nomes apresentados são fictícios. 
inclusive pelo delineamento das ações para atender às necessidades educacionais dos alunos. De fato, o currículo deve incorporar a realidade cultural de seus agentes e nortear o trabalho docente, a fim de atender às especificidades do alunado, tendo em vista que se "[...] é algo que se constrói, seus conteúdos e suas formas últimas não podem ser indiferentes aos contextos nos quais se configura" (Sacristán, 2000, p. 21).

Contudo, uma das pesquisadas, a professora Deise, destoou dos depoimentos dos outros segmentos, ao situar o currículo como sendo "[...] as disciplinas trabalhadas" (Profa Deise), uma vez que assim expressa uma visão de currículo tradicional, reduzindo-o a “[...] um conjunto de disciplinas e de conteúdos a serem 'passados' aos alunos, 'organizados numa grade curricular'” (Libâneo, 2004, p. 174). Entretanto, o currículo supera os conteúdos escolares previstos nas disciplinas, uma vez que compreende:

[...] o conjunto dos vários tipos de aprendizagens, aquelas exigidas pelo processo de escolarização, mas também aqueles valores, comportamentos, atitudes que se adquirem nas vivências cotidianas na comunidade, na interação entre professores, alunos, funcionários, nos jogos e no recreio e outras atividades concretas que acontecem na escola que denominamos ora currículo real ora currículo oculto. (Libâneo, 2004, p. 174)

Constatamos, através das diretrizes curriculares, que o currículo deve estar em consonância com os Parâmetros Curriculares Nacionais (PCN). Diante disso, indagamos à gestora e a uma coordenadora quanto à percepção que tinham a respeito dessa orientação. A primeira expressou que “Com certeza o currículo deve estar em consonância com os PCN, nós temos os PCN na escola e nós vamos estabelecer critérios e metas para trabalhar em cima dos documentos" (Gestora Gelsa).

Essa fala nos preocupou, tendo em vista que esses documentos oficiais pautaram as diretrizes curriculares da escola sem que ocorresse uma discussão crítica e consciente com o fim de uma construção própria. Como o nome mesmo sugere, trata-se de parâmetros que se configuram em aspectos pedagógicos e curriculares gerais, a fim de subsidiar a reflexão, a discussão e a tomada de decisões dos professores e professoras no interior das escolas.

Percebemos que, embora os PCN tenham sido apresentados desde 1995, ainda há pouco conhecimento dos profissionais de educação acerca da sua proposta, o que aponta falta do desenvolvimento de uma análise crítica dos seus pressupostos com os professores em exercício na escola.

Ao invés da gestora e coordenadora serem estimuladas a construir uma proposta com base na realidade da comunidade escolar, o que vimos foi a motivação, por parte do sistema de ensino, para legitimar as ações dos PCN, conforme relata a coordenadora: 
Isso aí a gente colocou, só citou, se você prestou bem atenção, a gente só citou, porque era uma das coisas que eles apontavam muito que a gente colocasse. Porque muito ali também eram orientações que a gente pegava, em reuniões que tinha, a gente saía anotando, entendeu? Como montar o PPP, que no início era aquela ... né? Aí, a gente pegava, anotava e aí a gente foi encaixando alguma daquelas pontuações que eles davam de orientação pra gente e a gente encaixou, mas você vê que foi só uma ... não tem nada que dê embasamento pra gente ir mais adiante, você vê que com relação a currículo é uma coisa meio solta ... É por isso que eu disse ali: a gente não considera mais nem projeto político-pedagógico. (Coordenadora Tércia).

Dessa forma, a pesquisada tece considerações sobre o PPP e o currículo com informações evasivas, demonstrando claramente que não houve, na escola, discussões coletivas sobre as diretrizes curriculares que propunham implementar, menos ainda sobre as implicações práticas dessas decisões na formação dos sujeitos.

Para fins de orientação do trabalho pedagógico, diante da inclusão de alunos com deficiência, investigamos o conhecimento das pesquisadas acerca das diretrizes curriculares expressas no PPP. Neste sentido, a gestora explicita que:

O PPP não direciona nada ainda de inclusão, embora a gente tenha todo o material que a gente vai estudar para introduzir. [0 PPP] é tão antigo, que naquele tempo, eu acho, nem se falava ainda de inclusão. Nós estamos aqui não tem nem seis meses, e no início são muitas mudanças, estamos ainda naquela fase de arrumar a casa. A partir do próximo ano é que nós vamos começar, mesmo, a executar as nossas ações. (Gestora Gelsa).

Dessa maneira, torna a destacar que o PPP da escola não contempla a inclusão de alunos com deficiência e, como o currículo faz parte do projeto, naturalmente, também acredita que as diretrizes não orientam o trabalho educativo nessa perspectiva.

Gelsa relaciona o período de construção do PPP (2005) com a falta de conhecimento acerca da inclusão, como forma de justificar a ausência de orientações pedagógicas capazes de promover a realização de uma prática consciente e comprometida com o desenvolvimento intelectual e social dos alunos. É importante destacarmos, porém, que a discussão sobre a inclusão escolar no Rio Grande do Norte começou a ser intensificada a partir do final da década de 1980, não justificando, portanto, que até o presente momento a escola tenha se mantido indiferente às necessidades educacionais específicas dos alunos.

0 currículo é determinado pelo contexto e, pelo que podemos observar, é urgente a necessidade de discussão sobre as diretrizes curriculares definidas no PPP, bem como o encaminhamento de orientações mais claras e a implementação de ações efetivas 
que contemplem também os alunos com deficiência intelectual, entre outros que também apresentam necessidades educacionais especiais.

Além disso, não há porque esperar mais um ano para concretizar direcionamentos que foram definidos há três anos. Sabemos que a construção curricular é um processo, mas devemos considerar que, nesse contexto, já existem diretrizes capazes de orientar o trabalho pedagógico inclusivo. É importante, também, o compartilhamento dessas orientações com toda a equipe da escola, assim como o aprofundamento, com vistas a garantir uma intervenção consciente e comprometida com a formação dos alunos.

A respeito do currículo, a coordenadora Tércia complementa, comentando as diretrizes curriculares existentes no PPP:

[...] não tem as orientações, não. Por isso que a gente vai sentar e direcionar. A gente não montou, até porque na Secretaria de Educação, na época, elas estavam sentando, direcionando os estudos com a gente pra montar, pra direcionar... Não é uma coisa muito fácil não, é meio complexo, pois alguns autores dizem uma coisa, outros dizem outra [...]. (Coordenadora Tércia).

Compreendemos que houve, na realidade, a apresentação de um documento organizado para cumprir uma exigência formal da SME. Assim, não ocorreu a participação dos profissionais em exercício, mesmo que a Lei de Diretrizes e Bases da Educação, Lei nº 9.394/96, oriente que é competência dos docentes a participação na construção do projeto pedagógico da escola. Isso nos faz inferir, ainda, que aqueles profissionais que participaram - e permanecem atuando na referida escola - não tinham conhecimento real sobre as diretrizes que estavam delineando e qual a sua finalidade.

Dessa forma, percebemos a expressão das dificuldades que permeiam o trabalho pedagógico e que acabam impedindo as possibilidades de construção da sua identidade por parte da comunidade escolar. Frente ao contexto, identificamos que muitas dessas dificuldades decorrem de lacunas deixadas na formação inicial e que, por ora, não são solucionadas na formação em serviço. Nossa inferência é confirmada na afirmação abaixo, apontando que as pesquisas, na área do currículo, têm mostrado que

[...] os professores encontram grandes dificuldades em assumir as novas propostas curriculares postas pelo chamado Movimento de Renovação Pedagógica e também pelos documentos emanados do MEC, em virtude de sua trajetória escolar, de sua formação profissional e também de suas representações e concepções acerca da escola e do currículo. (Santos, 2006, p. 161). 
Com isso, vem sendo aceita a ideia de que o currículo de formação docente deve ser orientado por algumas categorias como cultura, conhecimento, poder, ideologia, linguagem, história, discriminação, entre outras. A organização do currículo em torno dessas categorias possibilita aos docentes a compreensão sobre como grupos e indivíduos são oprimidos por questões ligadas às diferenças, e também favorece a intervenção docente no momento de elaboração do currículo (Armaline e Farber et al. apud Moreira, 2006). A necessidade de retomar as discussões acerca do currículo é apresentada pela coordenadora, ao expressar a consciência de que

[...] há a necessidade da escola rever esse currículo, esse projeto pra fazer essa questão, realmente, dessa inclusão. Está sendo todo o processo iniciado agora, [pois] mesmo com a presença de Roberto a gente ainda não fez essas devidas adaptações. Esse processo está começando a ser implementado. (Coordenadora Suzana).

Em sua percepção, portanto, as diretrizes curriculares não orientam o trabalho pedagógico frente aos alunos com deficiência. Situa, ainda, as ações que deverão ser implementadas, quando salienta que

No plano de trabalho eu estabeleci ações pra rever o projeto, inclusive é uma das ações do PDE. Rever o PPP é uma das ações do PDE, como está havendo essa necessidade nós vamos centralizar estudos sobre isso. No plano de trabalho colocamos estudos com a comunidade escolar, como um todo, porque ele vai conviver com todos os segmentos da escola, então, todo mundo tem que participar desse trabalho. Projetei, também, levantamento de dados para o mês de fevereiro. Os alunos que forem matriculados, vamos identificar essa clientela e também vamos promover reuniões com os pais, tanto para entrevistas (foi uma coisa que não foi realizada, mesmo com Roberto). Pedi a mãe só um diagnóstico, mas não fiz, houve essa falha [para conhecer] o estado dessa família, como se dá a realidade dele na família. Houve esse descuido, então, tudo isso está sendo implementado no projeto, inclusive eu coloquei o plano pra 2007 e 2008, pra corrigir essas falhas e ver o que a gente pode ir melhorando. (Coordenadora Suzana).

Como podemos perceber, houve a priorização do $\mathrm{PDE}^{3}$ em detrimento do PPP, quando a coordenadora ressalta que faz parte das ações do PDE rever o PPP. O PDE

3. O PDE é um Plano Estratégico de Gestão concebido no âmbito do FUNDESCOLA - Fundo de Fortalecimento da Escola que "enfatiza a 'gestão democrática' centrada numa concepção gerencialista e eficientista, como instrumento legal para organização do trabalho escolar. A autonomia escolar é garantida por um fundo repassado à escola, com vistas a estimular o quadro administrativo a tomar decisões que afetem materialmente a escola e a responsabilizar-se pelos resultados de suas decisões" (Fonseca; Toschi; Oliveira, 2004, p. 29). 
está associado à lógica gerencial, a qual negligencia a ação pedagógica da escola e limita sua autonomia com uma participação restrita. Assim, se compreendemos que a função da educação básica é socializar os conhecimentos construídos coletivamente ao longo das relações sociais, torna-se fundamental que o processo de planejamento seja participativo, no intuito de favorecer a finalidade da educação como direito social, bem como a igualdade e a construção de uma sociedade verdadeiramente inclusiva e equitativa (Araújo, 2008).

Diante disso, Suzana continua abordando o tema, reconhecendo a fragilidade da situação educacional do aluno, tendo em vista que

Ele do jeito que está ... essa questão de conteúdo, grade curricular, ele está prejudicado, pouco tem sido feito. Até aqui o que foi feito foi só a questão da sensibilização e do envolvimento social dele, mas a questão da evolução cognitiva, sobre esses outros aspectos ... quase nada foi feito (Coordenadora Suzana).

Percebemos, através do depoimento da coordenadora, a consciência da necessidade da escola, como um todo, mobilizar-se, reconhecendo a presença desses alunos, que têm o direito de estar incluídos efetivamente no processo de ensino e aprendizagem. Contudo, é incoerente, na sua fala, afirmar que “[...] esse processo está começando a ser implementado", considerando que os alunos com deficiência já estão matriculadas na escola há alguns anos e somente agora alguns profissionais começam a atentar para a necessidade da sua participação efetiva no contexto educativo, como é o caso da outra coordenadora, que destaca: "0 projeto político pedagógico não direciona nada para os alunos com necessidades especiais, se você der uma olhada nele direito, você vê que não contempla em nada" (Coordenadora Tércia).

Frente aos depoimentos, pudemos constatar uma discrepância entre o discurso e a prática, considerando que as diretrizes curriculares presentes no PPP da referida escola não são seguidas, minimamente, pelos profissionais envolvidos no processo educativo, ocasionando o comprometimento na formação global dos alunos.

Com isso, tornou-se evidente a falta de clareza quanto à dimensão das diretrizes delineadas, assim como a possibilidade da não-participação no processo de construção do currículo e, até mesmo, a falta de comprometimento dos profissionais que nela trabalham. Isso porque o desenvolvimento curricular “[...] é uma prática dinâmica e complexa que se fundamenta, planeia, realiza e avalia em momentos diferentes, mas relacionados entre si, que expressam uma mesma realidade" (Pacheco, 2005, p. 47).

De igual modo, a professora Valquíria expressou desconhecimento das diretrizes curriculares, de maneira que reforça a inexistência das orientações acerca da inclusão de alunos com deficiência na escola, ao situar que 
Na verdade, aqui na escola, esse ano tudo é novo, a direção é nova e eu também sou nova aqui nessa escola. Eu procurei saber e a resposta que encontrei, em relação a todos os documentos da escola, currículo, PPP, PDE, o que me disseram é que tá tudo precisando ser atualizado. A direção atual falou que, normalmente, era feito tudo nos bastidores, sem a participação de professor, de coordenador, a gente não sabe nem ao certo quem fazia essa documentação. A direção atual está com muita dificuldade porque já procurou conversar com o coordenador e ninguém tem noção de nada, porque nada era feito com a participação deles. Uma coisa que até elas estavam dizendo é que, agora, no segundo semestre, a gente vai ter que sentar e ver essas questões, porque no PDE, PPP existem ações pra serem executadas. Então, é interessante que essas ações sejam discutidas e sugeridas pelo grupo de professores, já que somos nós que temos que colocá-las em prática. Então, a gente, realmente, está vendo que a gente vai ter que ter vários momentos e vai ser muito oportuno pra gente estar colocando essas questões de pensar também num currículo, num PPP, tudo contemplando as crianças com necessidades especiais, já que [antes] não se tinha esse cuidado, pelo que a gente sabe. (Professora Valquíria).

De fato, essa fala evidencia a falta de conhecimento e/ou clareza acerca das diretrizes curriculares definidas. E mais, demonstra uma realidade escolar desarticulada pedagogicamente, pois não existiam orientações gerais, mas trabalhos individuais, em que cada profissional atuava a partir do seu conhecimento e da sua consciência, do que concebia como adequado. Esse tipo de intervenção foi confirmado por uma professora, ao falar sobre as diretrizes curriculares:

Pra dizer se é pra fazer isso ou aquilo, não. Quando a gente se reúne pra planejar, é que a coordenadora diz: vamos fazer isso, assim, que é melhor desenvolver a aula dessa maneira. Não de um modo especial pra aquele [aluno], mas para todos. (Professora Deise).

Isto evidenciou que as especificidades dos alunos, entre eles os que apresentam deficiência intelectual, são ignoradas pelos profissionais ao proporem situações de ensino amplas, sem discutir possibilidades capazes de envolvê-los efetivamente, garantindo a participação e o progresso deles na aprendizagem.

Nas falas, as pesquisadas demonstraram, assim, não perceberem que, definindo o currículo, a escola descreve suas intenções, sua função, bem como a forma de enfocála, a partir do contexto real, visto que é a prática que concretiza os objetivos propostos, que devem atender às necessidades dos alunos, no intuito de lhes assegurar progresso na aprendizagem.

Para tanto, concebendo o currículo como elemento favorecedor do processo inclusivo, por delinear toda e qualquer prática pedagógica no interior da escola, bem como 
enquanto elemento influenciador de toda a trajetória de vida educacional dos educandos, questionamos o entendimento das duas coordenadoras e de uma professora sobre a relação entre currículo e inclusão. Assim, a coordenadora destacava que ocorre:

[...] dentro das próprias metodologias, de como a gente vai trabalhar. Aí a gente direciona as atividades, pensando não só nos [alunos] ditos normais, mas nos que estão sendo incluídos, nos que estão... Não é nem voltado só ... direcionado só pra aqueles que a gente tem hoje [na escola], mas de uma maneira geral. (Coordenadora Tércia).

Tendo por base a perspectiva inclusiva, consequentemente, o currículo também se pauta numa metodologia capaz de envolver todos os alunos, inclusive aqueles com deficiência, bem como orienta a discussão e elaboração de atividades que considerem o seu desenvolvimento intelectual. Nesse sentido, a professora Valquíria aprofundou ainda mais a discussão, destacando que o

[...] currículo deve ser pensado para atender às necessidades da escola. Então, no currículo deve estar contemplado o que se considera que é importante ser trabalhado pra que a criança aprenda. Não adianta a gente dizer que vai ensinar da mesma forma, porque, em alguns casos, existe realmente a limitação e a gente precisa entender. (Professora Valquíria).

0 currículo, portanto, concretiza os objetivos da escola, orientando quanto aos conteúdos contemplados, a metodologia adotada e o tipo de avaliação do processo de aprendizagem dos alunos, devendo ser coerente com a realidade dos sujeitos, com vistas a ofertar um atendimento adequado às suas necessidades educacionais. Dessa forma, todas

[...] as finalidades que se atribuem e são destinadas implícita ou explicitamente à instituição escolar, de socialização, de formação, de segregação ou de integração social, etc., acabam necessariamente tendo um reflexo nos objetivos que orientam todo o currículo, na seleção de componentes do mesmo, desembocam numa divisão especialmente ponderada entre diferentes parcelas curriculares e nas próprias atividades metodológicas às quais dá lugar. (Sacristán, 2000, p. 17).

É através do currículo que a função social da escola pode ser efetivada. Se a escola se pauta nos pressupostos inclusivos, propõe objetivos capazes de acolher a diversidade do alunado, bem como define conteúdos, metodologia e formas de avaliação considerando as diversas possibilidades de aprendizagem, com o propósito de formar cidadãos críticos e ativos na construção de uma sociedade democrática e justa. 
Por outro lado, a coordenadora não consegue perceber a relação existente entre currículo e inclusão, em decorrência do processo inclusivo ainda não ter se efetivado na realidade escolar, enquanto instituição pública, pois situa que é “[...] difícil, já que essa inclusão, realmente, não está ainda bem trabalhada na realidade da escola pública, fica difícil de fazer essa relação" (Coordenadora Suzana).

Nesse sentido, corroboramos mais uma vez a posição de Sacristán (2000), anteriormente referenciada, uma vez que, embora os profissionais pesquisados apresentem uma retórica coerente com o processo inclusivo, percebemos os pressupostos integracionistas implícitos no fazer pedagógico que aludem. Além disso, não há le não houve, no momento de definição) o sentido de inclusão dos alunos com deficiência nas diretrizes curriculares e, ainda menos, no PPP. Dessa maneira, foram os objetivos estruturados com base no modelo da integração $0^{4}$, já superado, que vêm orientando a prática cotidiana dessa escola.

\section{Algumas considerações}

A apreciação do currículo é uma condição para conhecer e analisar o que é a escola como instituição cultural e de socialização, em termos reais e concretos. É através das ações desenvolvidas em função do currículo que a escola manifesta o seu valor. Por isso, o currículo é um elemento importante de referência para analisar o que a escola é, de fato, como instituição educacional e cultural.

Com isso, a partir da análise do currículo da escola, constatamos que as diretrizes curriculares expressam uma visão ampla de currículo, constituindo-se num elemento que engloba todas as atividades propostas pela escola. Essa concepção de currículo, complementada com o entendimento de que ele é responsável pelo delineamento das ações para atender às necessidades dos alunos, é confirmada através do posicionamento da maioria das participantes, exceto por uma professora, que aborda uma visão de currículo tradicional, reduzindo-o a um conjunto de disciplinas.

Verificamos, ainda, que o currículo da escola propõe a diversificação e a flexibilidade, no intuito de motivar o aluno e atender ao seu nível de aprendizagem. Situa cuidado ao selecionar os conteúdos programáticos, numa sequência lógica e com significância, a fim de permitir a formação de cidadãos conscientes, críticos e capazes de contribuir com a transformação da sociedade.

4. Modelo que - apesar de ter tido o mérito de contribuir para inserir a pessoa com deficiência na sociedade, desde que estivesse de, alguma forma, capacitada para superar barreiras nela existentes - representava um esforço unilateral (da pessoa com deficiência, sua família, de instituições especializadas e alguns profissionais) (Sassaki, 1997). 
Diante dos aspectos destacados no currículo analisado, podemos caracterizá-lo numa visão progressista, por ser aberto, preocupado com a seleção e organização dos conteúdos, com a flexibilidade na definição dos objetivos, com a busca pela diversificação dos procedimentos adotados, bem como do planejamento das atividades de ensino-aprendizagem, com base no nível de aprendizagem dos alunos.

No entanto, essas diretrizes, assim como o PPP, são desconhecidas pelas profissionais da escola, as quais argumentam que aquelas não orientam o trabalho educativo na perspectiva inclusiva, devido a sua fase de construção ser anterior à discussão sobre inclusão, assim como o currículo em vigência ter sido montado apenas para cumprir uma exigência da SME. Por isso, existe a necessidade de retomar, no coletivo, as discussões sobre o mesmo, com vistas à possibilidade de implementá-lo, efetivamente, na prática cotidiana.

Os posicionamentos apresentados pelas pesquisadas denunciaram, portanto, uma discrepância entre o discurso e a prática, considerando que as diretrizes curriculares não são discutidas, nem seguidas, minimamente, na realização do trabalho pedagógico, comprometendo, assim, a sua implementação no cotidiano escolar e, consequentemente, as respostas educativas aos alunos em geral, e, neste contexto, aos alunos com deficiência.

Isto decorre do fato de existir uma distância entre a teoria e a prática, que foi evidenciada por duas das três profissionais questionadas a respeito da relação entre currículo e inclusão. Apesar de perceberem o seu entrelaçamento - tendo em vista que o currículo concretiza os objetivos pretendidos pela escola - não foi mobilizado o grupo para a discussão e implementação das diretrizes curriculares. Além do desconhecimento, evidenciam, também, a falta de conhecimento teórico acerca dos princípios defendidos no currículo.

Nessa perspectiva, situamos a relevância da participação ativa dos profissionais na construção e implementação de um currículo: aberto, preocupado com a seleção e organização de conteúdos pautados na sua realidade; flexível na definição dos objetivos, na diversificação dos procedimentos adotados, bem como no planejamento das atividades de ensino-aprendizagem, com base no nível de aprendizagem dos alunos.

Isso porque, ao definir o currículo, a escola descreve suas intenções, sua função, bem como a forma de enfocá-la a partir do contexto real, visto que é a prática que concretiza os objetivos propostos, que devem atender às necessidades dos alunos e alunas, no intuito de assegurar o crescimento na sua aprendizagem.

Para tanto, através do currículo, a escola pode contribuir para efetivar a sua função social, pautando-se nos pressupostos inclusivos, propondo objetivos capazes de acolher as diferenças de alunos e alunas, bem como definindo conteúdos e metodologia com base nas diversas possibilidades de aprendizagem, com vistas a formar cidadãos críticos e ativos na construção de uma sociedade verdadeiramente democrática e justa. 


\section{Referências}

ALVES, Zélia Maria Mendes Biasoli; SILVA, Maria Helena, Galvão Freitas Dias da. Análise quantitativa de dados de entrevista: uma proposta. Paidéia, Ribeirão preto, v. 2, p. 61-69, 1992.

ARAÚJO, Suêldes de. 0 caminho das pedras para gestão escolar: o papel do gestor na implementação do projeto político-pedagógico. 2008. 187 p. Dissertação (Mestrado em Educação) - Universidade Federal do Rio Grande do Norte, Natal, 2008.

FONSECA, Marília; TOSCHI, Mirza Seabra; OLIVEIRA, João Ferreira de (Org.). Escolas gerenciadas: planos de desenvolvimento e projetos político-pedagógicos em debate. Goiânia: Ed. da UCG, 2004.

GIL, Antonio Carlos. Métodos e técnicas de pesquisa social. 3. ed. São Paulo: Atlas, 1999.

GOLDENBERG, Mirian. A arte de pesquisar: como fazer pesquisa qualitativa em ciências sociais. 7. ed. Rio de Janeiro: Record, 2003.

KRAMER, Sônia. Propostas pedagógicas ou curriculares: subsídios para uma leitura crítica. In: MOREIRA, Antonio Flávio Barbosa (Org.). Currículo: políticas e práticas. 9. ed. São Paulo: Papirus, 2006. LIBÂNEO, José Carlos. Organização e gestão da escola: teoria e prática. 5. ed. Goiânia: Alternativa, 2004. MOREIRA, Antonio Flávio Barbosa (Org.). Currículo: políticas e práticas. 9. ed. São Paulo: Papirus, 2006. PACHECO, José Augusto. Escritos Curriculares. São Paulo: Cortez, 2005.

PORTER, Gordon. Organização das escolas: conseguir o acesso e a qualidade através da inclusão. In: AINSCOW, Mel; et al. Caminhos para as escolas inclusivas. Lisboa: Instituto de Inovação Educacional, 1997. p. 33-48.

SACRISTÁN, J. G. O currículo: uma reflexão sobre a prática. Trad. Ernani Rosa. 3. ed. Porto Alegre: Artmed, 2000.

SANTOS, Lucíola Licínio de Castro Paixão. Identidades docentes em tempo de educação inclusiva. In: VEIGA, Ilma Passos Alencastro; AMARAL, Ana Lúcia (Org.). Formação de professores: políticas e debates. 3. ed. São Paulo: Papirus, 2006, p. 155 - 174 (Coleção Magistério: Formação e Trabalho Pedagógico).

SASSAKI, Romeu Kazumi. Inclusão: construindo uma sociedade para todos. Rio de Janeiro: WVA, 1997. SCHENEIDER, Magalis Bésser Dorneles. Subsídios para atuação pedagógica no cotidiano escolar inclusivo. Disponível em: <http://www.educacaoonline.pro.br/art_subsidios_para_acao.asp>. Acesso em: 2 fev. 2004.

TORRES GONZÁLEZ, José Antonio. Educação e diversidade: bases educativas e organizativas. Porto Alegre: Artmed, 2002.

Recebido em abril de 2011.

Aprovado em julho de 2011. 
Érika Soares de Oliveira possui mestrado em Educação (2010), pela Universidade Federal do Rio Grande do Norte. Docente da Secretaria Municipal de Educação de Natal/RN. Publicação recente: Currículo e inclusão de alunos com deficiência intelectual: algumas considerações sobre o papel do gestor escolar (In: Lúcia de Araujo Ramos Martins; Luzia Guacira dos Santos Silva (orgs.) Múltiplos olhares sobre a inclusão. João Pessoa: Editora Universitária da UFPB, 2009) em coautoria com Lúcia de Araújo Ramos Martins.

Lúcia de Araújo Ramos Martins, doutora em Educação pela Universidade Federal do Rio Grande do Norte. Atualmente, é professora Associada III da Universidade Federal do Rio Grande do Norte. Publicação recente: Inclusão: compartilhando saberes (5a. ed. Petrópolis: Vozes, 2011) em coorganização com José Pires; Francisco Ricardo Lins e Gláucia Nascimento da Luz. E-mail: luc.martinsaterra.com.br. 


\section{Linhas Críticas}

A revista foi criada em 1995 com o objetivo de divulgar a produção científica de docentes e pesquisadores da Universidade de Brasília, como também editar artigos de autores de outros centros de investigação do Brasil e do exterior. Conta, desde o início, com um Comitê e Conselho Editorial qualificado, reconhecido nacional e internacionalmente. A partir de 2005 o periódico passou a contar com uma versão online na REDALYC - Red de Revistas Científicas de América Latina y el Caribe, España y Portugal, disponível em: www.redalyc.com.

\section{NÚMEROS TEMÁTICOS}

No 33 (vol. 17) Educação especial inclusiva No 32 (vol. 17) Docência, formação e gestão No 31 (vol. 16) Hermenêutica, teoria crítica e educação No 30 (vol. 16) Educação profissional e tecnológica No 29 (vol. 15) Formação de profissionais da educação No 28 (vol. 15) Políticas educacionais e novas formas de regulação NNo 26 (vol. 14) Docência na educação superior No 24 (vol. 13) Educação e novas tecnologias No 22 (vol. 12) Educação, formação e aprendizagem No 21 (vol. 11) Edição comemorativa: 10 anos de Linhas Críticas No 20 (vol. 11) Políticas públicas para a educação No 18 (vol. 10) Gestão na educação No 17 (vol. 9) Novas tecnologias na educação No 16 (vol. 9) Educação especial No 15 (vol. 8) Criatividade na educação No 12 (vol. 7) Formação de professores e financiamento da educação No 7-8 ( vol. 4) Psicodrama na educação No 5-6 (vol. 3) Filosofia para crianças No 3-4 (vol. 2) Faculdade de Educação da UnB: um ideário pedagógico à altura do Brasil 